\title{
Update on Adult Immunizations
}

Robert M. Wolfe, $M D$

The past few years have seen numerous additions and modifications to the current immunization schedules. Starting with the 2010 to 2011 influenza season, the Centers for Disease Control and Prevention have recommended universal annual influenza vaccination for all persons without a contraindication who are 6 months of age and older, including healthy persons aged 19 to 49 years. Hepatitis B vaccination is now recommended for all susceptible diabetics $\leq 60$ years of age. One dose of tetanus toxoid, reduced diphtheria toxoid, and acellular pertussis vaccine, adsorbed, is recommended to replace one tetanus and diphtheria toxoids adsorbed (adult) vaccination for all adults, including those 65 years of age or older, who are anticipating contact with infants and unvaccinated pregnant women (preferably during the second or third trimester). All adult vaccines remain underused. This article will summarize the most recent changes in the adult immunization recommendations of the Advisory Committee on Immunization Practices of the Centers for Disease Control and Prevention. (J Am Board Fam Med 2012;25: 496-510.)

Keywords: Adult, Immunization, Prevention, Review, Vaccination

Rates of vaccination of adults have consistently fallen behind vaccination rates for children and adolescents. The Centers for Disease Control and Prevention (CDC) analyzed data from the 2010 National Health Interview Survey to assess adult vaccination rates and found them to be low for most routinely recommended vaccines. Rates of the 3 vaccines included in Healthy People (HP) 2020pneumococcal, herpes zoster, and hepatitis B (for health care personnel $[\mathrm{HCP}]$ )—were well below the respective target levels: for pneumococcal vaccine, rates in 2010 were $59.7 \%$ for persons aged $>65$ years (HP2020 target of 90\%) and 18.5\% for per-

This article was externally peer reviewed.

Submitted 15 November 2010; revised 7 February 2012; accepted 15 February 2012.

From the NorthShore University HealthSystem, Lincolnwood, IL; and the Department of Family Medicine, University of Chicago, Pritzker School of Medicine, Chicago, IL.

Funding: The author is on the speakers bureau of Merck, Inc. and has been on the speakers bureau and served as a consultant for Sanofi Pasteur. He has received honoraria from both companies for these services. Both companies manufacture vaccines mentioned in this article. Author is member of the STFM Group on Immunization Education, contributes content to SHOTS program mentioned in Table 5 , and receives a small stipend for this.

Conflict of interest: none declared.

Corresponding author: Robert M. Wolfe, NorthShore University HealthSystem, 6810 N. McCormick Blvd., Lincolnwood, IL 60712 (E-mail: rwolfe1@uchicago.edu). sons at high risk aged 18 to 64 years (HP2020 target, $60 \%$ ); for herpes zoster vaccine, rates were $14.4 \%$ for persons aged $\geq 60$ years (HP2020 target, $30 \%)$; and for the hepatitis vaccine for HCP, the rates were $63.2 \%$ (HP2020 target, 90\%). For adults for whom tetanus toxoid, reduced diphtheria toxoid, and acellular pertussis vaccine, adsorbed (Tdap) status could be assessed, coverage was only $8.2 \%$; for HCP Tdap coverage was $20.3 \%{ }^{1}$

The CDC estimated that 40,000 to 50,000 vaccine-preventable deaths occur every year in the United States and estimates the health care burden of vaccine-preventable diseases at $\$ 10$ billion. $^{2}$ Family physicians are specialists in preventive care and can be leaders in seeing that adult patients get the full benefit of protection against vaccine-preventable diseases. This article summarizes the most significant recent changes in the US adult immunization schedule.

\section{Influenza Vaccine}

\section{Universal Influenza Immunization}

Since the 2010 to $2011 \mathrm{flu}$ season, the CDC has recommended that all persons should be immunized annually against influenza, starting from the age of 6 months, which is the youngest age for which any influenza vaccine is approved. The 2011 
to 2012 US seasonal influenza vaccine virus strains are identical to those contained in the 2010 to 2011 vaccine and includes the 2009 pandemic influenza A (H1N1) vaccine virus strain. ${ }^{3}$

\section{Available Influenza Vaccines}

There are 2 types of influenza vaccine available for administration to adults: the trivalent inactivated influenza vaccine (TIV) and the live attenuated influenza vaccine (LAIV). LAIV is administered intranasally and contains the same influenza viruses as TIV. The live viruses in LAIV are temperature sensitive and do not replicate effectively at the human core body temperature; thus, they cannot produce disease. However, the LAIV viruses are adapted to cold, which enables them to replicate in the slightly cooler temperature of the nasopharyngeal mucosa and produce immunity. A recent metaanalysis comparing TIV with LAIV concluded that LAIV seems to be slightly more effective than TIV in children. ${ }^{4}$ Studies comparing TIV with LAIV in adults have shown conflicting results. ${ }^{5,6}$ The CDC has stated that both TIV and LAIV have been demonstrated to be effective in children and adults and that there is insufficient data directly comparing the effectiveness of these 2 types of influenza vaccines to identify whether one vaccine might offer a clear advantage over the other in a particular population. ${ }^{3}$ LAIV is not approved for adults $\geq 50$ years of age and may not be given to pregnant women or persons who are immunocompromised, which includes those with chronic pulmonary (including asthma), cardiovascular (except hypertension), renal, hepatic, neurological/neuromuscular, hematologic, or metabolic (including diabetes) disorders or with immunosuppression (including that caused by medications or HIV).

A new influenza vaccine, trivalent influenza vaccine intradermal (TIVI) (Fluzone Intradermal, Sanofi Pasteur, Swiftwater, PA), was licensed in May 2011. This vaccine is indicated for persons aged 18 through 64 years and is administered intradermally via a single-dose, prefilled microinjection syringe. TIVI contains $9 \mu \mathrm{g}$ of each flu strain in $0.1 \mathrm{~mL}$ total volume versus intramuscular TIV preparations, which contain $15 \mu \mathrm{g}$ of each strain in $0.5 \mathrm{~mL}$ total volume. The preferred site for administration is over the deltoid muscle. The most common adverse reactions are local: erythema, induration, swelling, pain, and pruritus. With the exception of pain, these reactions occurred more frequently than with the intramuscular vaccine but generally resolved within 3 to 7 days. $^{7}$ The CDC has not indicated a preference for this vaccine over other influenza vaccines. ${ }^{3}$

Trivalent influenza vaccine high dose (TIVHD; Fluzone High-Dose, Sanofi Pasteur), available since the 2010 to 2011 influenza season, contains $60 \mu \mathrm{g}$ of hemagglutinin per vaccine strain (rather than $15 \mu \mathrm{g}$ per strain as in other TIV preparations). TIVHD is available as an alternative TIV for persons aged $\geq 65$ years. The rationale for the higher antigen dose is to stimulate a better antibody response in the elderly, who have a weaker response to influenza vaccines because of immunosenescence. The CDC has indicated no preferential recommendation for this vaccine over other influenza vaccines indicated for use in the elderly. ${ }^{3}$

A web page listing influenza vaccines available in the United States for the current influenza season and their age indications is available at http:// www.immunize.org/catg.d/p4072.pdf (Acquired from Immunization Action Coalition on April 22, 2012); the link is updated continuously to match current recommendations and availability.

\section{Pneumococcal Polysaccharide Vaccine}

Pneumococcal disease causes significant illness and death worldwide. The most serious manifestations of illness are pneumonia, pneumococcal sepsis and meningitis. In 2005 the World Health Organization estimated that 1.6 million persons died of pneumococcal disease throughout the world, mainly the elderly and small children. ${ }^{8}$ In 2005 in the United States, more than 40,000 cases and more than 4,400 deaths from invasive pneumococcal disease (IPD; bacteremia and meningitis) were estimated to have occurred. More than half of these cases occurred in adults for whom the pneumococcal polysaccharide vaccine was indicated. ${ }^{9}$

Pneumococcal polysaccharide vaccine (23-valent) (PPSV23; Pneumovax 23, Merck, Whitehouse Station, NJ) was licensed in 1983. It contains antigens against strains that account for $88 \%$ of pneumococci that cause sepsis. The vaccine is recommended for all persons 65 years of age and older and also is recommended for certain high-risk groups (see Table 1). In 2008 the CDC added smokers and asthmatics aged 19 to 64 years to the high-risk list because these groups have an increased risk of IPD. Observational studies generally have shown that PPSV23 is $50 \%$ to $80 \%$ effective 


\begin{tabular}{ll}
\hline Who needs to be vaccinated with PPV23? & 1. Vaccinate all previously unvaccinated adults aged 65 years and older. \\
2. Vaccinate all adults who smoke cigarettes. \\
3. Vaccinate persons aged 2 to 64 years who: \\
- have chronic cardiovascular disease (eg, congestive heart failure, \\
cardiomyopathy); chronic pulmonary disease (eg, chronic obstructive \\
pulmonary disease, emphysema, adults with asthma); or diabetes \\
mellitus or those who are cochlear implant patients. \\
- have chronic liver disease (including cirrhosis), are alcoholic, or have a \\
cerebrospinal fluid leak. \\
- live in special environments or social settings (eg, adults aged 50 to 64 \\
years who are Alaska Natives or certain American Indian populations if \\
recommended by local health authorities). \\
4. Vaccinate persons aged 2 to 64 years with functional or anatomic asplenia \\
(including persons with sickle cell disease or splenectomy patients). \\
5. Vaccinate immunocompromised persons aged 2 years and older, including \\
those with HIV infection, leukemia, lymphoma, Hodgkin disease, \\
multiple myeloma, generalized malignancy, chronic renal failure \\
(including dialysis patients), or nephrotic syndrome; those receiving \\
immunosuppressive therapy (including long-term systemic \\
corticosteroids); and those who have received an organ or bone marrow \\
transplant.
\end{tabular}

*Persons with asymptomatic or symptomatic HIV infection should be vaccinated as soon as possible after their diagnosis is confirmed (per Prevention of pneumococcal disease: recommendations of the Advisory Committee on Immunization Practices (ACIP). MMWR Recomm Rep. 1997;46(RR-8):1-24).

${ }^{\dagger}$ When cancer chemotherapy or other immunosuppressive therapy is being considered (eg, for patients with Hodgkin disease or those who undergo organ or bone marrow transplantation), PPV23 should be given 2 weeks before or 3 months after immunosuppressive or radiation therapy. Vaccination during chemotherapy or radiation therapy should be avoided (per Prevention of pneumococcal disease: recommendations of the Advisory Committee on Immunization Practices (ACIP). MMWR Recomm Rep. 1997;46(RR-8):1-24).

Adapted with permission from Pneumococcal polysaccharide vaccine (PPSV) CDC answers your questions. From the Immunization Action Coalition, St. Paul, MN. Available online at: www.immunize.org/catg.d/p2015.pdf.

in preventing IPD in immunocompetent adults and that it may reduce the severity of pneumonia in those patients who develop pneumonia after vaccination. ${ }^{10}$ Recent studies even have indicated that pneumococcal vaccination may prevent myocardial infarction and stroke by reducing thrombosis caused by inflammation. ${ }^{11-13}$

Persons who are immunocompromised, such as HIV patients or cancer patients undergoing chemotherapy or radiation therapy, have a particularly high rate of IPD. Health care workers administering PPSV23 should be proactive and have patients newly diagnosed with any malignancy vaccinated immediately upon diagnosis because a full immune response to the vaccine requires at least 2 weeks and is weakened by chemotherapy or radiation therapy. ${ }^{9}$ If chemotherapy or radiotherapy is initiated less than 2 weeks after administering PPSV23, the CDC recommends that the patient be considered un- vaccinated, and should be revaccinated at least 3 months after therapy is discontinued if immune competence has been restored.

Persons $\geq 65$ years of age who have had one prior dose of PPV23 should receive a second dose if $\geq 5$ years have elapsed since the previous dose. Only one revaccination dose of PPV23 is recommended for certain high-risk persons (see Table 1); a third dose is not presently recommended by the CDC because of a lack of proven efficacy. ${ }^{9}$ However, some recent studies have shown a good antibody response to a primary and booster dose of PPSV23. ${ }^{14-16}$

In December 2011, the US Food and Drug Administration (FDA) approved a pneumococcal 13-valent conjugate vaccine (PCV13; Prevnar 13, Wyeth Pharmaceuticals, Radnor, PA) to help protect adults aged 50 and over from pneumococcal pneumonia. At this time the optimal use of PCV13 in adults, alone or in a series with PPV23, has not been determined. ${ }^{17}$ 
Recognizing the importance of pneumococcal immunizations, the Centers for Medicare \& Medicaid Services has added screening for and administration of pneumococcal immunization as a quality measure for hospital inpatients. Beginning January 1, 2012, rates of pneumococcal immunization will be assessed for all inpatients $\geq 65$ years of age and inpatients 5 to 64 years of age with highrisk conditions. ${ }^{18}$ After October 2013, reported data will be available to the public at http:// www.hospitalcompare.hhs.gov/. (See Table 2 for Level of Evidence [LOE].)

\section{Herpes Zoster Vaccine}

Varicella zoster virus (VZV) causes 2 clinical conditions. The first, varicella (chickenpox), was widespread in childhood before the era of varicella vaccination and has infected $98 \%$ of the adult US population. The virus travels through affected sensory nerves to the sensory dorsal root ganglia next to the spinal cord, where it enters a latent phase. The second stage, herpes zoster, occurs when the virus reactivates in one dorsal root ganglion and travels back to the skin, where it causes a localized unilateral vesicular rash. ${ }^{19}$ Reactivation seems to be related to declining cell-mediated immunity and is more common with advancing age and in patients with immunosuppressive conditions such as neoplastic disease, organ transplant recipients, persons receiving immunosuppressive medication, and HIV patients. ${ }^{20}$ Pain is the most common symptom of herpes zoster, affecting about $75 \%$ of cases. Lingering pain after a zoster infection is called postherpetic neuralgia (PHN) and is commonly defined as pain lasting more than 1 to 3 months after the primary infection. PHN can be excruciatingly painful and can last for months and occasionally for years. Antiviral therapy after the onset of shingles has not shown efficacy for the prevention of PHN. $^{21}$

The herpes zoster (shingles) vaccine (ZOS; Zostavax, Merck), was approved by the FDA in May 2006 for use in persons $\geq 60$ years of age. Although the FDA licensed ZOS for use in adults aged 50 to 59 years in March 2011, the Advisory Committee on Immunization Practices (ACIP) so far has declined to extend a formal recommendation for this age range because of concerns about limitations in the vaccine supply and uncertainty about the duration of the vaccine's protection in younger adults. ${ }^{22}$ ZOS is similar to the varicella vaccine (VAR; Varivax, Merck); it is made from the live-attenuated Merck-Oka viral strain but contains 14 times as much viral antigen as is present in varicella vaccine. In the Shingles Prevention Study, more than 38,000 adults (median age, 69 years; range, 59-99 years) were followed for a mean of 3.1 years after receiving either vaccine or placebo. Vaccination with ZOS reduced the incidence of herpes zoster by $51 \%$ and the incidence of PHN by $66 \% .^{19,23}$ Side effects were mild, and there was no significant increase in serious adverse events in the vaccine group when compared with the placebo group. A subsequent cohort study found ZOS to be as effective, and in some subpopulations, more effective, than was indicated by the Shingles Prevention Study. ${ }^{24}$

ZOS is recommended by the ACIP for all adults 60 years of age and older (LOE: A; see Table 2). ${ }^{19}$ A history of zoster is not a contraindication to vaccination because there is no way to document the level of herpes zoster immunity and vaccine side effects are minimal. In addition, immunization will give additive immunity against shingles; this

Table 2. Practice Recommendations and Level of Evidence

\begin{tabular}{lcc}
\hline Practice Recommendations & Level of Evidence & Reference \\
\hline $\begin{array}{l}\text { Give pneumococcal polysaccharide vaccine (PSV23, Pneumovax) } \\
\text { for prevention of pneumococcal disease to following persons: }\end{array}$ & A & A \\
Immunocompetent persons and persons aged $\geq 65$ years of age. & B \\
$\begin{array}{l}\text { Persons aged 2-64 years with chronic cardiovascular disease, } \\
\text { chronic pulmonary disease, or diabetes mellitus. }\end{array}$ & A \\
$\begin{array}{l}\text { Persons aged 2-64 years with alcoholism, chronic liver disease, } \\
\text { or cerebrospinal fluid leaks. }\end{array}$ & \\
$\begin{array}{l}\text { Give herpes zoster vaccine (Zostavax) for the prevention of } \\
\text { herpes zoster and its complications in persons } \geq 60 \text { years } \\
\text { without contraindications. }\end{array}$ & 54 \\
\hline
\end{tabular}


may be particularly important in view of a recent study indicating higher rates of recurrence of shingles than previously believed. ${ }^{3}$ ZOS is an attenuated live-virus vaccine and is not indicated for persons with certain immune-suppressing conditions (see Table 3).

A study showing a reduced VZV antibody response when ZOS was given simultaneously with PSV23 (Pneumovax) led the manufacturer to recommend that these 2 vaccines should not be given simultaneously and that there should be a 4-week interval between administration of the 2 vaccines. ${ }^{25}$ However, the CDC continues to recommend that these vaccines be given simultaneously, if indicated, because VZV immunity is cell mediated and does not correlate well with antibody levels. ${ }^{22,26}$ This is supported by an observational study published in 2011 that found no evidence that simultaneous administration of the 2 vaccines would impair zoster immunity. ${ }^{27}$ (See Table 2 for Level of Evidence.)

\section{Human Papillomavirus Vaccine}

Human papillomavirus (HPV) is estimated to be the most common sexually transmitted disease; more than $80 \%$ of sexually active American women will acquire an HPV infection by the age of 50 years with seroprevalence of HPV type 16 (the most carcinogenic type) as high as $41 \% .{ }^{28} \mathrm{HPV}$ is responsible for more than $99 \%$ of cervical cancer and is believed to be responsible for $90 \%$ of anal cancers and $40 \%$ of vulvar, vaginal, or penile cancers. $^{29}$ In developed countries, HPV has passed tobacco use to become the major cause of oropharyngeal cancer (found in $45 \%$ to $90 \%$ of cases). ${ }^{30}$ Four HPV types account for the most serious illness: high-risk types 16 and 18 are found in $70 \%$ of cervical cancers, and low-risk types 6 and 11 cause $90 \%$ of genital warts. HPV type 16 is responsible for $>85 \%$ of HPV-related head and neck squamous cell cancers. ${ }^{30}$ Most HPV infections clear within 8 months to 2 years, but high-risk HPV subtypes are more likely to persist and lead to precancer and cancer. Progression from high-grade precancerous lesions to cancer is estimated to take 10 years. $^{31}$

Two vaccines are available to prevent HPV infections. HPV4 (Gardasil, Merck) contains types 16 and 18 (high risk) and types 6 and 11 (low risk). HPV2 (Cervarix, GlaxoSmithKline, Research Triangle Park, NC) contains types 16 and 18 (high risk). Both HPV2 and HPV4 are composed of virus-like particles prepared from the recombinant L1 capsid protein of HPV-neither is a live vaccine. Both vaccines have shown efficacy well over $90 \%$ for preventing precancerous cervical lesions. ${ }^{32}$

HPV4 vaccine is licensed for girls and young women 9 through 26 years of age for the prevention of cervical, vulvar, vaginal, and anal cancers caused by HPV types 16 and 18; genital warts caused by HPV types 6 and 11; and precancerous or dysplastic lesions caused by HPV types 6, 11, 16, and 18. As of October 2011, HPV4 also is recommended by the ACIP for boys and men 9 through 21 years of age for the prevention of anal cancer caused by HPV types 16 and 18; for the prevention of anal dysplasias and precancerous lesions caused by HPV types $6,11,16$, and 18 ; and for the prevention of genital warts caused by HPV types 6 and 11. The ACIP also recommends HPV4 for previously unvaccinated men 22 to 26 years of age who are immunocompromised, who test positive for HIV infection, or who have sex with men. However, any man may receive the vaccine through age 26 if desired. The HPV2 vaccine is licensed for girls and women ages 10 through 25 years for the prevention of cervical cancers and precancers. The ACIP recommends the same age range, 9 to 26 years of age, for both HPV2 and HPV4. If a man or woman reaches age 27 before the vaccination series is complete, the vaccine series may still be completed if it had been started before the 27th birthday. ${ }^{32}$ The ACIP recommends the same 3 -dose schedule for either vaccine. Each dose is $0.5 \mathrm{~mL}$ and is administered intramuscularly. The second dose is administered 1 to 2 months after the first dose, and the third dose is administered 6 months after the first dose. The ACIP has not expressed a preference for one HPV vaccine over the other for vaccination of women.

Although HPV vaccines are not recommended to be given during pregnancy, testing for pregnancy is not necessary before giving the vaccine, and no intervention is needed if a patient is found to be pregnant after receiving HPV vaccine. Women receiving the HPV vaccine should be counseled to continue routine Papanicolaou screening for cervical cancer according to existing guidelines. Although it is biologically plausible that HPV2 and HPV4 could prevent oropharyngeal cancers, it may take several decades before this effect could be detectable in population studies ${ }^{30}$ (see the box titled, "Can HPV 


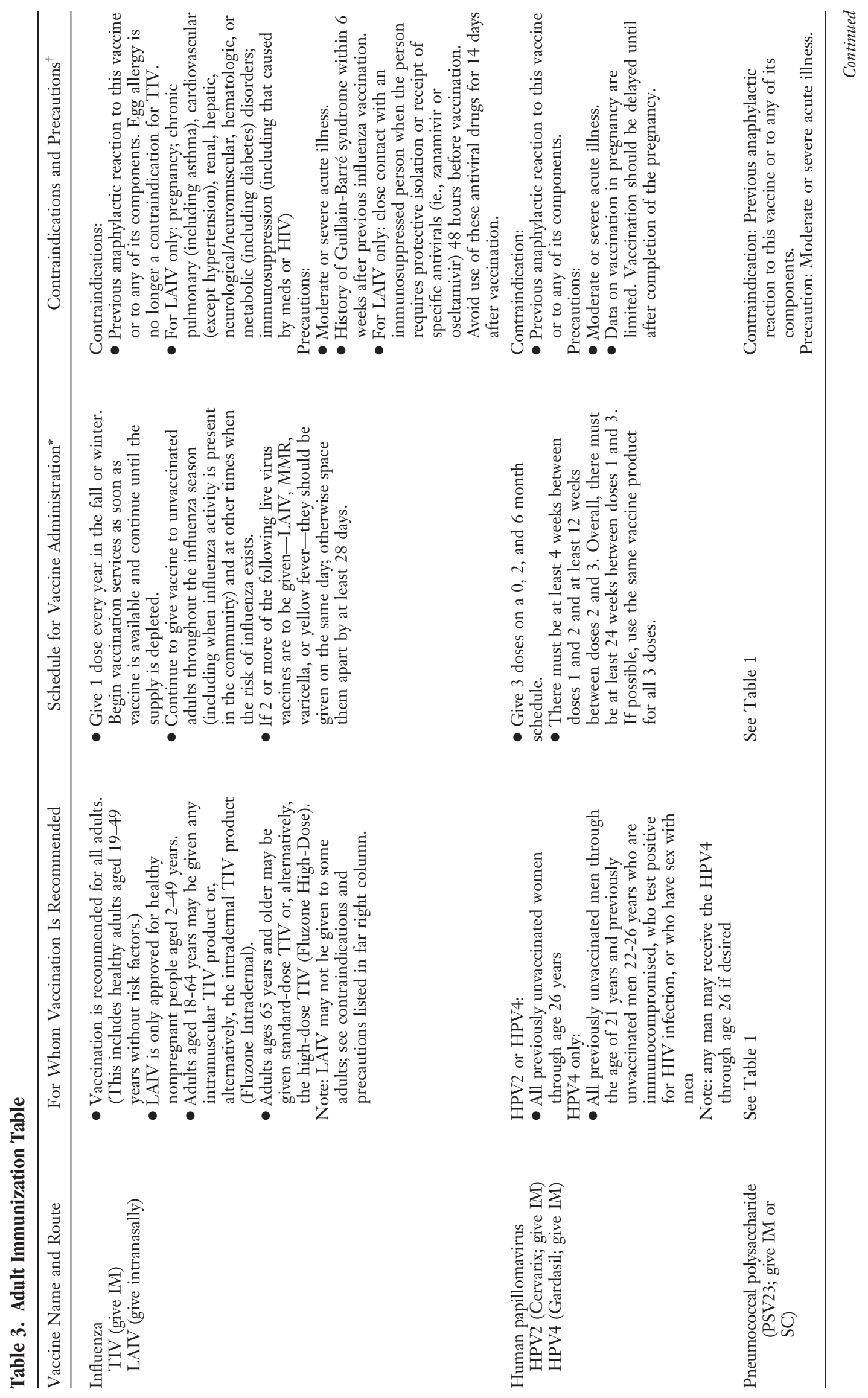




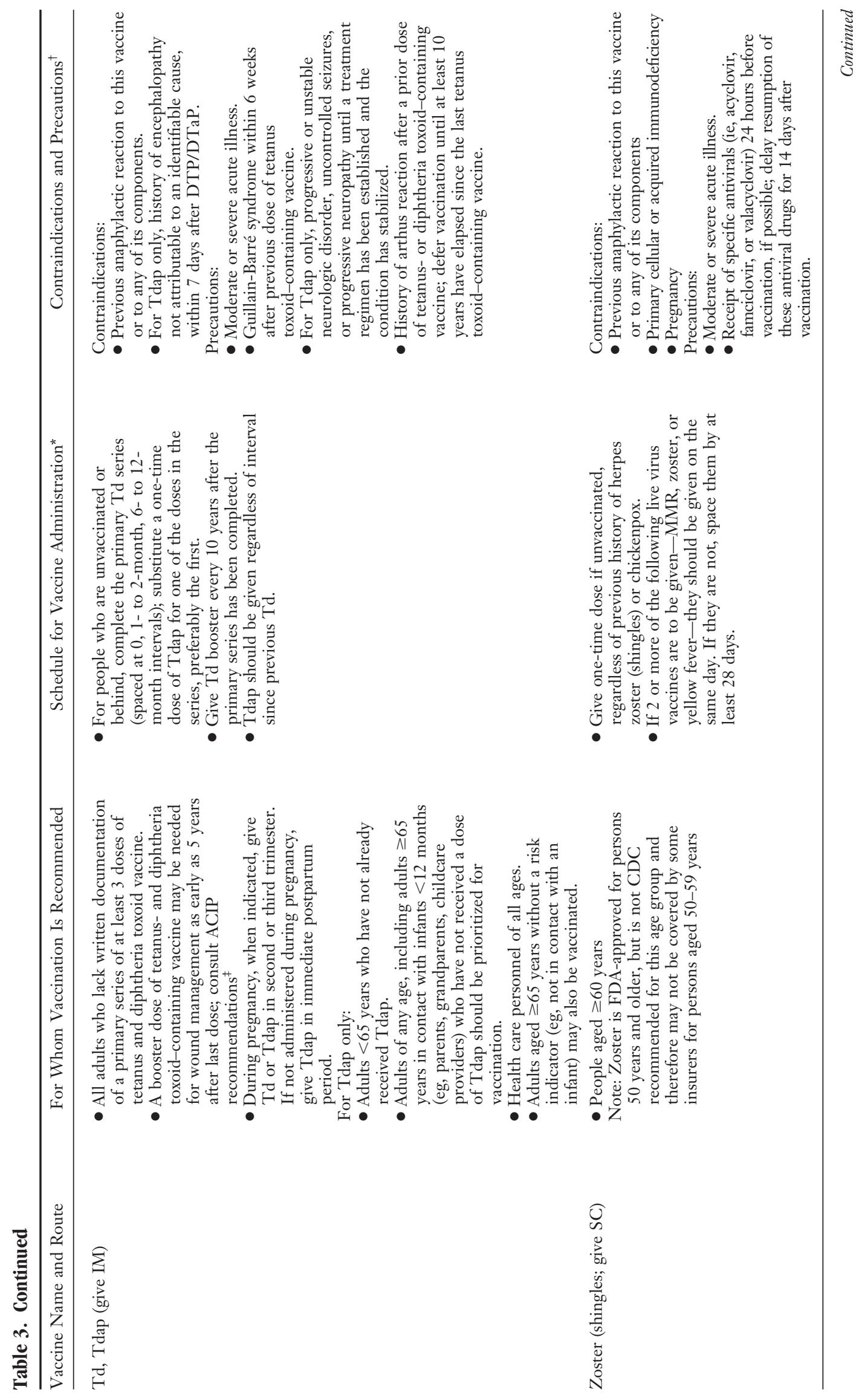




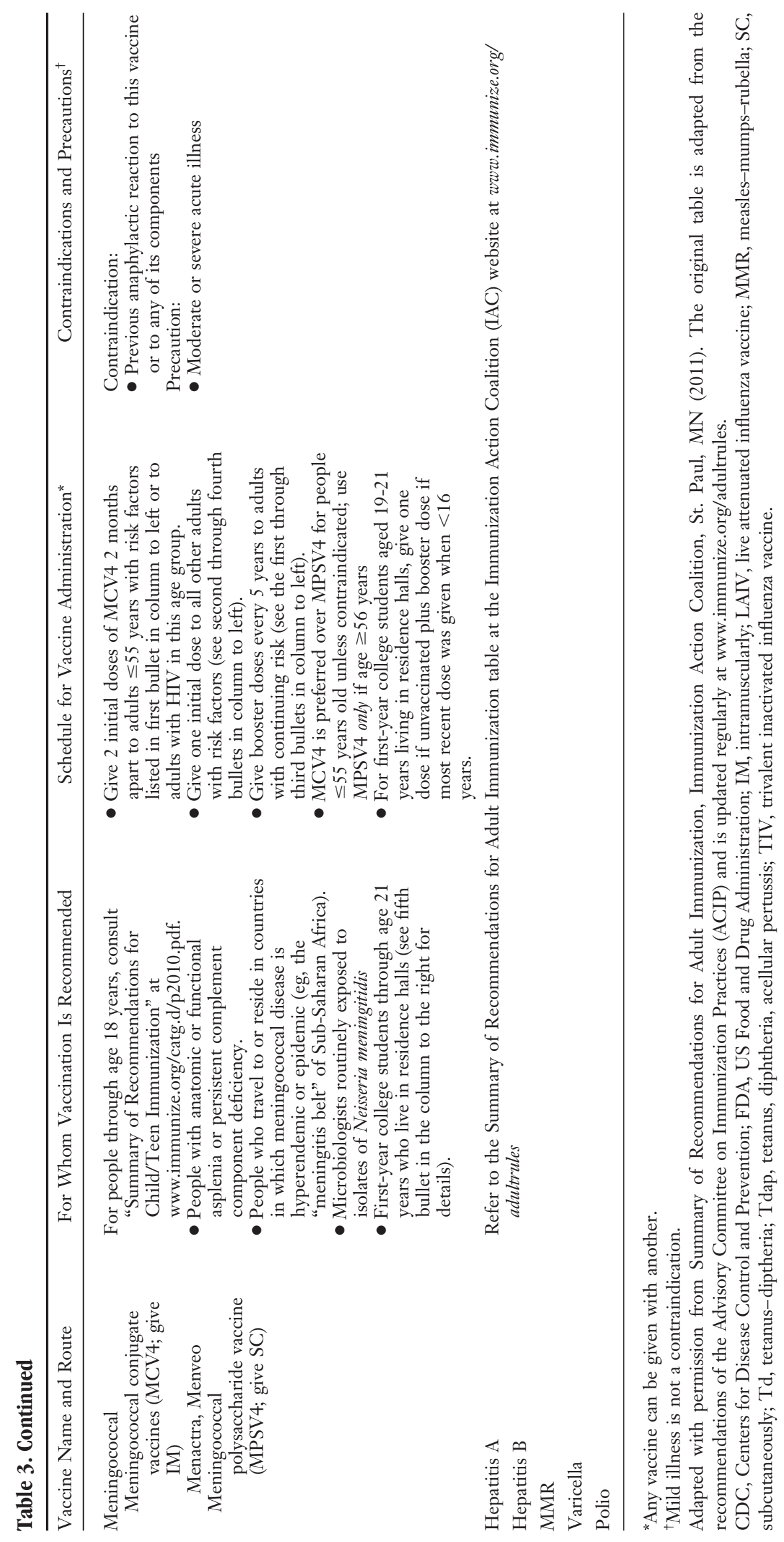


Vaccination Prevent Cancer of the Head and Neck?"). Information about administration, precautions, and contraindication are listed in Table 2.

\section{Tetanus-Diphtheria-Pertussis Vaccine}

Tetanus and diphtheria have become rare in the United States, and most cases occur in adults who have not completed a primary immunization series. However, pertussis, a coughing illness caused by the bacteria Bordetella pertussis, remains an endemic disease, with the true number of cases estimated to be between 800,000 and 3.3 million annually in the United States. ${ }^{40}$ Pertussis incidence has been increasing gradually since the early 1980s. More than 25,000 cases were reported in 2004, the largest number since $1959 .{ }^{41}$ In 2010, 9,143 cases of pertussis (including 10 infant deaths) were reported throughout California. This is the most cases reported in 63 years, when 9,394 cases were reported in 1947.

Adolescents and adults serve as a reservoir of disease because pertussis immunity wanes 4 to 12 years after the completion of childhood vaccination. ${ }^{42}$ Giving a booster dose of pertussis vaccine to adults is considered essential to reduce the burden of disease and protect newborns from infection, especially during the vulnerable first 2 months of life before the first pertussis vaccination.

Vaccines containing acellular pertussis were first licensed for use in adolescents and adults in 2005. Tdap is written with small $d$ and $p$ letters to indicate that the dose of diphtheria and acellular pertussis toxoid in the vaccine has been reduced in the adolescent/adult formulations to minimize the incidence of adverse effects. Two Tdap vaccines are currently available. Boostrix (GlaxoSmithKline) is approved for persons 10 through 64 years of age. Adacel (Sanofi Pasteur) is approved for persons 11 through 64 years of age. In response to the 2010 pertussis epidemic in California, the ACIP voted on October 27, 2010, to approve the off-label use of Tdap in adults aged $\geq 65$ years who anticipate contact with children aged $\leq 12$ months to protect both themselves and the infant. ${ }^{43}$

The ACIP recommends that Tdap should replace a single dose of the tetanus-diphtheria vaccine (Td) for adults aged $\geq 19$ years or older who have not previously received a dose of Tdap. Tdap also can be substituted for any $\mathrm{Td}$ dose in the 3-dose primary series. A dose of Tdap is recom- mended for pregnant women (preferably given in the third or late second trimester), postpartum women, those with close contacts with infants aged $<12$ months, and all HCP with direct patient contact if they have not previously received Tdap. When giving Tdap to protect an infant, no minimum interval needs to be adhered to; a dose of Tdap can be given immediately after a dose of $\mathrm{Td}$ in such cases. ${ }^{44}$ Ideally, these adults should receive Tdap at least 2 weeks before they are in close contact with the infant. Tdap, if given during pregnancy, preferably should be administered during the third or late second trimester (after 20 weeks' gestation). If not administered during pregnancy, Tdap should be administered immediately postpartum. $^{43}$

\section{Meningococcal/Varicella/Measles-Mumps- Rubella/Polio/Hepatitis A/Hepatitis B}

Some adults will require catch-up vaccination with these vaccines, particularly HCP and travelers. A summary of ACIP recommendations for immunization of HCP can be found in Table $4 .{ }^{45}$ Key updates are given below.

\section{Meningococcal}

Two quadrivalent meningococcal conjugate vaccines (MCV4) are now available: Menactra (Sanofi Pasteur), for persons aged 2 to 55 years, and Menveo (Novartis, East Hanover, NJ), for persons aged 11 to 55 years. A quadrivalent meningococcal polysaccharide vaccine (MPSV4), Menomune (Sanofi Pasteur), still is available for use in adults $\geq 56$ years of age.

The ACIP now recommends revaccination with MCV4 after 5 years for adults previously vaccinated with MCV4 or MPSV4 who remain at increased risk for infection (eg, adults with anatomic or functional asplenia or microbiologists or travelers with prolonged exposure). Either MCV4 vaccine may be used to revaccinate people aged 11 to 55 years who need a second dose, regardless of which vaccine was used for the first dose. ${ }^{46} \mathrm{In}$ addition, the ACIP has now recommends a booster dose 5 years after the first MCV4 dose for those who received their initial dose at ages 13 to $15 .{ }^{47}$ These changes were made because antibody levels were found to decline over time, and people ages 16 to 21 , particularly college freshmen living in dormitories, are considered to be at increased risk for 
Table 4. Summary of Main Changes* from 1997 Advisory Committee on Immunization Practices/Hospital ${ }^{\dagger}$ Infection $^{*}$ Control Practices Advisory Committee Recommendations for Immunization of Health Care Personnel

\begin{tabular}{|c|c|}
\hline Hepatitis B & $\begin{array}{l}\text { HCP and trainees in certain populations at high risk for chronic hepatitis } \mathrm{B} \text { (eg, those born in countries } \\
\text { with high and intermediate endemicity) should be tested for HBsAg and anti-HBc/anti-HBs to } \\
\text { determine infection status. }\end{array}$ \\
\hline \multirow[t]{2}{*}{ Influenza } & $\begin{array}{l}\text { Emphasize that all HCP, not just those with direct patient care duties, should receive an annual } \\
\text { influenza vaccination. }\end{array}$ \\
\hline & $\begin{array}{l}\text { Comprehensive programs to increase vaccine coverage among HCP are needed; influenza vaccination } \\
\text { rates among HCP within facilities should be measured and reported regularly. }\end{array}$ \\
\hline \multirow[t]{2}{*}{ MMR } & $\begin{array}{l}\text { History of disease is no longer considered adequate presumptive evidence of measles or mumps } \\
\text { immunity for HCP; laboratory confirmation of disease was added as acceptable presumptive evidence } \\
\text { of immunity. History of disease has never been considered adequate evidence of immunity for } \\
\text { rubella. }\end{array}$ \\
\hline & $\begin{array}{l}\text { The footnotes have been changed regarding the recommendations for personnel born before } 1957 \text { in } \\
\text { routine and outbreak contexts. Specifically, guidance is provided for } 2 \text { doses of MMR for measles and } \\
\text { mumps protection and } 1 \text { dose of MMR for rubella protection. }\end{array}$ \\
\hline \multirow[t]{3}{*}{ Pertussis } & $\begin{array}{l}\text { HCP, regardless of age, should receive a single dose of Tdap as soon as feasible if they have not } \\
\text { previously received Tdap. }\end{array}$ \\
\hline & $\begin{array}{l}\text { The minimal interval was removed, and Tdap now can be administered regardless of interval since the } \\
\text { last tetanus- or diphtheria-containing vaccine. }\end{array}$ \\
\hline & $\begin{array}{l}\text { Hospitals and ambulatory care facilities should provide Tdap for HCP and use approaches that } \\
\text { maximize vaccination rates. }\end{array}$ \\
\hline \multirow[t]{4}{*}{ Varicella } & Criteria for evidence of immunity to varicella were established. For HCP they include: \\
\hline & Written documentation with 2 doses of vaccine; \\
\hline & Laboratory evidence of immunity or laboratory confirmation of disease; \\
\hline & $\begin{array}{l}\text { Diagnosis of history of varicella disease by health care provider or diagnosis of history of herpes zoster } \\
\text { by health care provider. }\end{array}$ \\
\hline \multirow[t]{2}{*}{ Meningococcal } & $\begin{array}{l}\text { HCP with anatomic or functional asplenia or persistent complement component deficiencies should } \\
\text { now receive a } 2 \text {-dose series of meningococcal conjugate vaccine. HCP with HIV infection who are } \\
\text { vaccinated should also receive a } 2 \text {-dose series. }\end{array}$ \\
\hline & Those HCP who remain in groups at high risk are recommended to be revaccinated every 5 years. \\
\hline
\end{tabular}

*Updated recommendations made since publication of the 1997 summary of recommendations (CDC Immunization of health-care workers: recommendations of the Advisory Committee on Immunization Practices [ACIP] and the Hospital Infection Control Practices Advisory Committee [HICPAC]. MMWR 1997;46[No. RR-18]).

'Is now "Healthcare."

CDC, Centers for Disease Control and Prevention; HBsAg, hepatitis B surface antigen; anti-HBc, hepatitis B core antibody; anti-HBs, hepatitis B surface antibody; HCP, health care personnel; MMR, measles, mumps, rubella; Tdap, tetanus toxoid, reduced diptheria toxoid, and acellular pertussis vaccine, adsorbed.

Reprinted with permission from: Centers for Disease Control and Prevention. Immunization of health-care personnel: recommendations of the Advisory Committee on Immunization Practices (ACIP). MMWR Recomm Rep 2011;60(RR-7):1-45.

meningococcal disease. However, college freshmen who were vaccinated at age $\geq 16$ years do not need revaccination unless they are also in a high-risk category.

\section{Varicella}

All healthy adults should be assessed for varicella immunity. Evidence of immunity includes documentation of age-appropriate vaccination, laboratory evidence of immunity (or confirmation of disease), or diagnosis of varicella or zoster by a health care provider. Birth in the United States before 1980 is considered evidence of immunity, except for HCP, pregnant women, and immunocompromised persons, who require other evidence of immunity. Those who do not have evidence of immu- nity should receive 2 doses of single-antigen varicella vaccine 4 to 8 weeks apart. Varicella vaccination should be considered for HIV-infected adults with a $\mathrm{CD}^{+}$T-lymphocyte count of $\geq 200$ $\mathrm{mm}^{3}$; these individuals should receive 2 doses separated by 3 months. ${ }^{48}$ Pregnant women should be screened for varicella immunity; one dose given postpartum when indicated, with a second dose 4 to 8 weeks later.

\section{Hepatitis A}

A hepatitis $\mathrm{A} /$ hepatitis $\mathrm{B}$ combination vaccineTwinrix (GlaxoSmithKline) - can be given in an accelerated 4-dose schedule to protect travelers who need to depart in less than 1 month. Doses are given at 0,7 , and 21 days and 12 months. ${ }^{49}$ 
Family physicians who wish to stay current with the most recent updates in vaccine recommendations can get up-to-date information at these sites:

\begin{tabular}{|c|c|c|}
\hline $\mathrm{CDC}$ & $\begin{array}{l}\text { The Healthcare Professional website of the National } \\
\text { Immunization Program of the CDC has extensive } \\
\text { current information on immunizations and has an } \\
\text { Adult Immunization Scheduler program available } \\
\text { for free download. }\end{array}$ & www.cdc.gov/vaccines/hcp.htm \\
\hline $\begin{array}{l}\text { Immunization Action } \\
\text { Coalition }\end{array}$ & $\begin{array}{l}\text { The Immunization Action Coalition is a nonprofit } \\
\text { organization based in St. Paul, Minnesota. Their } \\
\text { website contains extensive, easy-to-access } \\
\text { informational materials for providers and patients, } \\
\text { and features IAC Express, a free weekly email } \\
\text { immunization newsletter for health professionals. }\end{array}$ & www.immunize.org/ \\
\hline SHOTS by STFM & $\begin{array}{l}\text { The Group on Immunization Education of the } \\
\text { Society of Teachers of Family Medicine (STFM) } \\
\text { created the SHOTS program, developed with } \\
\text { support from the CDC. } \\
\text { SHOTS by STFM is a free point-of-care } \\
\text { immunization information system that can be } \\
\text { accessed online or as a stand-alone program } \\
\text { compatible with iPhone, Android, and Blackberry. } \\
\text { SHOTS contains the complete immunization } \\
\text { schedules for children, adults, and persons with } \\
\text { special medical conditions. In addition, } \\
\text { information can be quickly viewed for each } \\
\text { individual vaccine regarding immunization basics, } \\
\text { high-risk indications, adverse reactions, } \\
\text { contraindications, administration, and catch-up } \\
\text { schedules. }\end{array}$ & www.immunizationed.org/ShotsOnline.aspx \\
\hline
\end{tabular}

CDC, Centers for Disease Control and Prevention.

For unvaccinated adults who are acutely exposed to the hepatitis A virus or are traveling to areas of high prevalence who do not have time to complete a 2-dose hepatitis A vaccine series, a single dose of hepatitis A vaccine now can be used as an alternative to immunoglobulin. For adults younger than age 40 , vaccine is preferred; for persons $\geq 40$ years of age, immunoglobulin is preferred but vaccine is acceptable. Older adults, immunocompromised persons, and persons with chronic liver disease or other chronic medical conditions planning to depart in $\leq 2$ weeks should receive the initial dose of vaccine and immunoglobulin can be administered simultaneously $(0.02 \mathrm{~mL} / \mathrm{kg})$ at a separate anatomic injection site. ${ }^{50}$

The CDC recommends hepatitis A vaccination for all previously unvaccinated persons who anticipate close personal contact (eg, household contact or regular babysitting) with an international adoptee from a country of high or intermediate endemicity during the first 60 days after arrival of the adoptee in the United States. The first dose of the 2-dose hepatitis A vaccine series should be administered as soon as adoption is planned, ideally $\geq 2$ weeks before the arrival of the adoptee. ${ }^{51}$

\section{Hepatitis B}

Hepatitis $B$ Vaccination for Diabetics $\geq 60$ Years Old

In December 2011 the ACIP recommended that all previously unvaccinated adults aged 19 to 59 years with diabetes mellitus (both type 1 and type 2) be vaccinated against hepatitis $B$ as soon as possible after a diagnosis of diabetes is made. ${ }^{52}$ The rationale was the finding that diabetics have approximately double the risk of acquiring a new hepatitis B infection; this increased risk seems to be associated with assisted blood glucose monitoring (when equipment is shared and adequate hand hygiene procedures are not used). Although the risk also is present for diabetics $\geq 60$ years old, hepatitis $B$ vaccination is less cost-effective in this age range. The CDC notes that a health care provider may still wish to vaccinate a diabetic $\geq 60$ years of age after assessing their risk, particularly regarding the patient's need for assisted blood glucose monitoring in long-term care facilities and the likelihood of experiencing chronic sequelae if infected with the hepatitis $\mathrm{B}$ virus. ${ }^{52}$ 


\section{Persons at High Risk for Sexual Transmission of Hepatitis $B$}

The most common source of hepatitis B infection in the United States is sexual contact. Heterosexual transmission accounts for $39 \%$ of new cases, and men who have sex with men account for $24 \%$, whereas intravenous drug use accounts for $16 \%$ of new cases of hepatitis B infection. The CDC recommends that persons with multiple sexual partners (eg, persons with more than one sex partner during the previous 6 months), men who have sex with men, and all persons seeking evaluation of or treatment for sexually transmitted diseases should be vaccinated against hepatitis $\mathrm{B} .{ }^{53}$ Serologic testing before vaccination only is recommended for adult populations with a prevalence of hepatitis B virus infection of $>20 \%$ (eg, injection-drug users, incarcerated persons, men who have sex with men, and persons born in countries with high levels of endemic hepatitis B virus infection). Prevaccination testing can be done with a single test, hepatitis B core antibody (anti-HBc) or with a panel of tests (eg, hepatitis B surface antigen and hepatitis B surface antibody [anti-HBs]). The CDC does not recommend delaying vaccination until the test results are reviewed; the first vaccine dose typically should be administered immediately after collection of the blood sample for serologic testing. ${ }^{53}$

\section{Keeping Current with Vaccines}

To help providers keep current with changing immunization recommendations, a number of regularly updated web-based resources are available: see Table 5.

\section{References}

1. CDC. Adult vaccination coverage-United States, 2010. MMWR Morb Mortal Wkly Rep 2012;61:66-72.

2. Infectious Diseases Society of America, Robert Wood Johnson Foundation, Trust for America's Health. Adult immunization: shots to save lives. Washington, DC: Trust for America's Health, the Infectious Diseases Society of America, and the Robert Wood Johnson Foundation; 2010. Available from: http://healthyamericans.org/report/73/adultimmunization-2010. Accessed May 22, 2012.

3. CDC. Prevention and control of influenza with vaccines: recommendations of the Advisory Committee on Immunization Practices (ACIP), 2011. MMWR Morb Mortal Wkly Rep 2011;60:1128-32.

4. Rhorer J, Ambrose CS, Dickinson S, et al. Efficacy of live attenuated influenza vaccine in children: A meta- analysis of nine randomized clinical trials. Vaccine 2009;27:1101-10.

5. Monto AS, Ohmit SE, Petrie JG, et al. Comparative efficacy of inactivated and live attenuated influenza vaccines. N Engl J Med 2009;361:1260-7.

6. Tosh PK, Boyce TG, Poland GA. Flu myths: dispelling the myths associated with live attenuated influenza vaccine. Mayo Clin Proc 2008;83:77-84.

7. Fluzone [package insert]. Swiftwater, PA: Sanofi Pasteur Inc.; 2011.

8. World Health Organization. Pneumococcal conjugate vaccine for childhood immunization-WHO position paper. Wkly Epidemiol Rec 2007;82:93-104.

9. Centers for Disease Control and Prevention. Pneumococcal disease. In: Epidemiology and Prevention of Vaccine-Preventable Diseases. Atkinson W, Wolfe S, Hamborsky J, eds. 12th ed., second printing. Washington DC: Public Health Foundation; 2012:233-48. Available from: http://www.cdc.gov/vaccines/pubs/pinkbook/ pneumo.html. Accessed May 22, 2012.

10. World Health Organization. 23-Valent pneumococcal polysaccharide vaccine. WHO position paper. Wkly Epidemiol Rec 2008;83:373-84.

11. Corrales-Medina VF, Madjid M, Musher DM. Role of acute infection in triggering acute coronary syndromes. Lancet Infect Dis 2010;10:83-92.

12. Vila-Córcoles A. Vaccinate your child and save its grandparents from a heart attack? Current perspectives in antipneumococcal vaccination. J Intern Med 2009;266:432-44.

13. Hung IFN, Leung AYM, Chu DWS, et al. Prevention of acute myocardial infarction and stroke among elderly persons by dual pneumococcal and influenza vaccination: a prospective cohort study. Clin Infect Dis 2010;51:1007-16.

14. Nichol KL. Pneumococcal vaccination and revaccination in the elderly population. J Infect Dis 2010; 201:659-61.

15. Musher DM, Manoff SB, McFetridge RD, et al. Antibody persistence 10 years after first and second doses of 23 -valent pneumococcal polysaccharide vaccine, and immunogenicity and safety of second and third doses in older adults. Hum Vaccin 2011;7:919-28.

16. Hammitt LL, Bulkow LR, Singleton RJ, et al. Repeat revaccination with 23 -valent pneumococcal polysaccharide vaccine among adults aged 55-74 years living in Alaska: no evidence of hyporesponsiveness. Vaccine 2011;29:2287-95.

17. Musher DM, Sampath R, Rodriguez-Barradas MC. The potential role for protein-conjugate pneumococcal vaccine in adults: what is the supporting evidence? Clin Infect Dis 2011;52:633-40.

18. Specifications Manual, Version 4.0c. Discharges 01/ 01/2012 to 06/30/2012. Available from: http://www. qualitynet.org/dcs/ContentServer? $\mathrm{c}=$ Page\&page name $=$ QnetPublic $\% 2$ FPage $\% 2 F Q n e t$ Tier4\&cid $=$ 1228767363466. Accessed May 22, 2012. 
19. Harpaz R, Ortega-Sanchez IR, Seward JF. Prevention of herpes zoster: recommendations of the Advisory Committee on Immunization Practices (ACIP). MMWR Recomm Rep 2008;57(RR-5):1-30; quiz CE2-4.

20. Gnann JW, Whitley RJ. Herpes zoster. N Engl J Med 2002;347:340-6.

21. Li Q, Chen N, Yang J, et al. Antiviral treatment for preventing postherpetic neuralgia. Cochrane Database Syst Rev 2009;(2):CD006866.

22. Centers for Disease Control and Prevention. Update on herpes zoster vaccine: licensure for persons aged 50 through 59 years. MMWR Morb Mortal Wkly Rep 2011;60:1528.

23. Singh A, Englund K. Q: Who should receive the shingles vaccine? Cleve Clin J Med 2009;76:45-8.

24. Tseng HF, Smith N, Harpaz R, Bialek SR, Sy LS, Jacobsen SJ. Herpes zoster vaccine in older adults and the risk of subsequent herpes zoster disease. JAMA 2011;305:160-6.

25. MacIntyre C, Egerton T, McCaughey M, et al. Concomitant administration of zoster and pneumococcal vaccines in adults $\geq 60$ years old. Abstract presented at: ICAAC/IDSA 2008 Joint Meeting, October 2528, 2008, Washington, DC.

26. Centers for Disease Control and Prevention. Vaccines and preventable diseases: herpes zoster vaccination for health care professionals. 2011. Available at: http://www.cdc.gov/vaccines/vpd-vac/shingles/ hcp-vaccination.htm. Accessed February 3, 2012.

27. Tseng HF, Smith N, Sy LS, Jacobsen SJ. Evaluation of the incidence of herpes zoster after concomitant administration of zoster vaccine and polysaccharide pneumococcal vaccine. Vaccine 2011;29:3628-32.

28. Markowitz LE, Dunne EF, Saraiya M, Lawson HW, Chesson H, Unger ER. Quadrivalent human papillomavirus vaccine: recommendations of the Advisory Committee on Immunization Practices (ACIP). MMWR Recomm Rep 2007;56(RR-2):1-24.

29. Centers for Disease Control and Prevention. Human papillomavirus. In: Epidemiology and Prevention of Vaccine-Preventable Diseases. Atkinson W, Wolfe S, Hamborsky J, eds. 12th ed., second printing. Washington DC: Public Health Foundation; 2012: 139-50. Available from: http://www.cdc.gov/vaccines/ pubs/pinkbook/hpv.html. Accessed May 22, 2012.

30. D'Souza G, Dempsey A. The role of HPV in head and neck cancer and review of the HPV vaccine. Prev Med 2011;53(Suppl 1):S5-11.

31. Broomall E, Reynolds S, Jacobson R. Epidemiology, clinical manifestations, and recent advances in vaccination against human papillomavirus. Postgrad Med 2010;122:121-9.

32. Centers for Disease Control and Prevention. FDA licensure of bivalent human papillomavirus vaccine (HPV2, Cervarix) for use in females and updated HPV vaccination recommendations from the Advisory Committee on Immunization Prac- tices (ACIP). MMWR Morb Mortal Wkly Rep 2010;59:626-9.

33. Gillison ML. Human papillomavirus-associated head and neck cancer is a distinct epidemiologic, clinical, and molecular entity. Semin Oncol 2004;31:744-54.

34. Kreimer AR, Clifford GM, Boyle P, Franceschi S. Human papillomavirus types in head and neck squamous cell carcinomas worldwide: a systematic review. Cancer Epidemiol Biomarkers Prev 2005;14: 467-75.

35. Chaturvedi AK, Engels EA, Pfeiffer RM, et al. Human papillomavirus and rising oropharyngeal cancer incidence in the united states. J Clin Oncol 2011;29: 4294-301.

36. D'Souza G, Kreimer AR, Viscidi R, et al. Casecontrol study of human papillomavirus and oropharyngeal cancer. N Engl J Med 2007;356:1944-56.

37. Dufour X, Beby-Defaux A, Agius G, Lacau St Guily J. HPV and head and neck cancer. Eur Ann Otorhinolaryngol Head Neck Dis 2012;129:26-31.

38. Gillison ML, Broutian T, Pickard RKL, et al. Prevalence of oral HPV infection in the United States, 2009-2010. JAMA 2012;307:693-703.

39. Gillison ML. Human papillomavirus-related diseases: oropharynx cancers and potential implications for adolescent HPV vaccination. J Adolesc Health 2008; 43(4 Suppl):S52-60.

40. Cherry JD. The epidemiology of pertussis: a comparison of the epidemiology of the disease pertussis with the epidemiology of Bordetella pertussis infection. Pediatrics 2005;115:1422-7.

41. Centers for Disease Control and Prevention. Pertussis. In: Epidemiology and Prevention of VaccinePreventable Diseases. Atkinson W, Wolfe S, Hamborsky J, eds. 12th ed., second printing. Washington DC: Public Health Foundation; 2012:215-32. Available from: http:// www.cdc.gov/vaccines/pubs/pinkbook/pert.html. Accessed May 22, 2012.

42. Wendelboe AM, Van Rie A, Salmaso S, Englund JA. Duration of immunity against pertussis after natural infection or vaccination. Pediatr Infect Dis J 2005; 24(5 Suppl):S58-61.

43. Centers for Disease Control and Prevention. Updated recommendations for use of tetanus toxoid, reduced diphtheria toxoid and acellular pertussis vaccine (Tdap) in pregnant women and persons who have or anticipate having close contact with an infant aged $<12$ months-Advisory Committee on Immunization Practices (ACIP), 2011. MMWR Morb Mortal Wkly Rep 2011;60:1424-6.

44. Atkinson W, Kroger A. IAC Express 2010. Issue number 871: June 2, 2010. Ask the experts. Available from: http://www.immunize.org/express/issue871.asp. Accessed January 15, 2012.

45. Centers for Disease Control and Prevention. Immunization of health-care personnel: recommendations of the Advisory Committee on Immunization Practices (ACIP). MMWR Recomm Rep 2011;60(RR-7):1-45. 
46. Centers for Disease Control and Prevention. Updated recommendation from the Advisory Committee on Immunization Practices (ACIP) for revaccination of persons at prolonged increased risk for meningococcal disease. MMWR Morb Mortal Wkly Rep 2009;58:1042-3.

47. Centers for Disease Control and Prevention. Updated recommendations for use of meningococcal conjugate vaccines-Advisory Committee on Immunization Practices (ACIP), 2010. MMWR Morb Mortal Wkly Rep 2011;60:72-6.

48. Marin M, Güris D, Chaves SS, Schmid S, Seward JF. Prevention of varicella: recommendations of the Advisory Committee on Immunization Practices (ACIP). MMWR Recomm Rep 2007;56(RR-4):1-40.

49. Centers for Disease Control and Prevention. Notice to readers: FDA approval of an alternate dosing schedule for a combined hepatitis $\mathrm{A}$ and $\mathrm{B}$ vaccine (Twinrix). MMWR Morb Mortal Wkly Rep 2007; 56:1057.

50. Centers for Disease Control and Prevention. Update: prevention of hepatitis A after exposure to hepatitis A virus and in international travelers. Updated recommendations of the Advisory Committee on Immunization Practices (ACIP). MMWR Morb Mortal Wkly Rep 2007;56:1080-4.

51. Centers for Disease Control and Prevention. Updated recommendations from the Advisory Committee on Immunization Practices (ACIP) for use of hepatitis A vaccine in close contacts of newly arriving international adoptees. MMWR Morb Mortal Wkly Rep 2009;58:1006-7.

52. Centers for Disease Control and Prevention. Use of hepatitis $\mathrm{B}$ vaccination for adults with diabetes mellitus: recommendations of the Advisory Committee on Immunization Practices (ACIP). MMWR Morb Mortal Wkly Rep 2011;60:1709-11.

53. Mast EE, Weinbaum CM, Fiore AE, et al. A comprehensive immunization strategy to eliminate transmission of hepatitis B virus infection in the United States: recommendations of the Advisory Committee on Immunization Practices (ACIP). Part II: immunization of adults. MMWR Recomm Rep 2006; 55(RR-16):1-33; quiz CE1-4.

54. Prevention of pneumococcal disease: recommendations of the Advisory Committee on Immunization Practices (ACIP). MMWR Recomm Rep 1997;46(RR8):1-24. Available at: http://www.cdc.gov/mmwr/ preview/mmwrhtml/00047135.htm. Accessed May 22, 2012.

55. Government of Canada PHAOC. Statement on the recommended use of herpes zoster vaccine: an Advisory Committee Statement-Canada Communicable Disease Report (CCDR). Vol. 0.35. ACS-1, Public Health Agency of Canada. Available at: http:// www.phac-aspc.gc.ca/publicat/ccdr-rmtc/10vol36/acs1/index-eng.php. Accessed May 22, 2012. 


\section{Can HPV Vaccination Prevent Cancer of the Head and Neck?}

There is mounting evidence that HPV causes not only cervical and anal cancer but also is responsible for $\sim 25 \%$ of head and neck squamous cell carcinoma (HNSCC). The majority of these HPVassociated HNSCCs are oropharyngeal (tonsillar and base of tongue) squamous cell cancers (OSCCs), and in developed countries HPV is detected in $45 \%$ to $90 \%$ of these cases. ${ }^{30}$ There is strong evidence connecting HPV as a cause of these tumors, both on a molecular level and in epidemiologic studies showing a strong connection between OSCC, rates of oral HPV, and HPV sexual exposure. ${ }^{30,33}$ Of HPV-positive OSCC, $\sim 90 \%$ are positive for high-risk HPV type 16, the type responsible for the majority of cervical cancers. ${ }^{34}$ Whereas HPV-negative OSCC has been steadily de-

Figure 1. Incidence rates for overall oropharyngeal cancer, human papillomavirus (HPV)-positive oropharyngeal cancers, and HPV-negative oropharyngeal cancers during 1988 to 2004 in Hawaii, Iowa, and Los Angeles. (From Chaturvedi AK, Engels EA, Pfeiffer RM et al Human papillomavirus and rising oropharyngeal cancer incidence in the united states. J Clin Oncol 2011;29:4294-301 (Ref. 49). Reprinted with permission.)

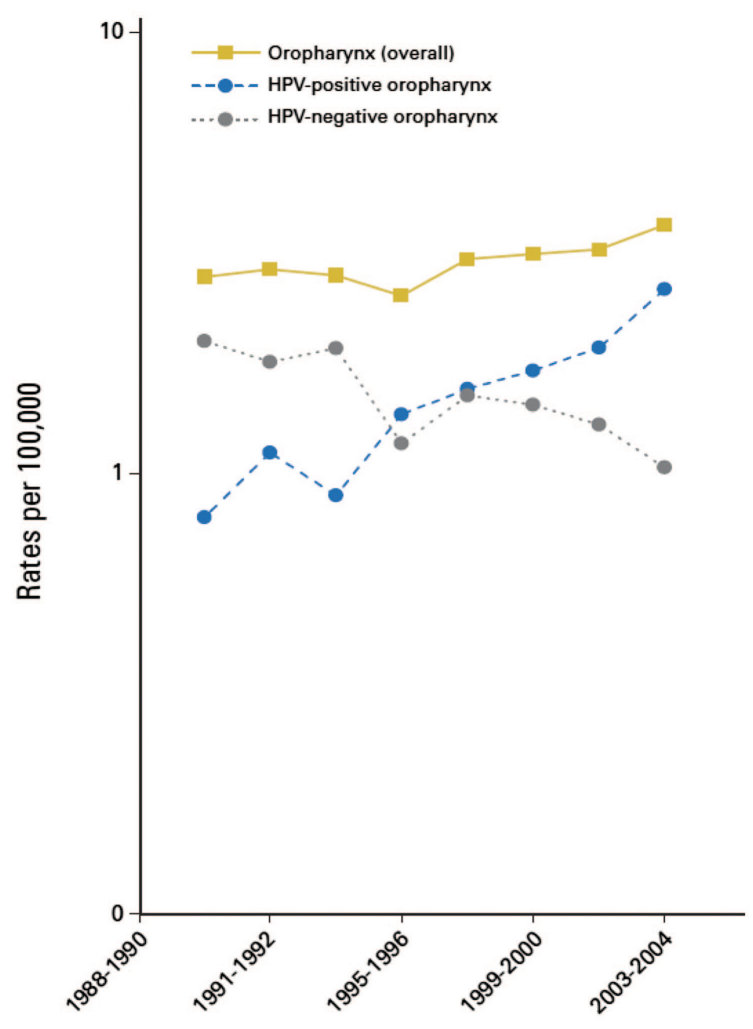
clining in the United States, paralleling the decline in smoking, HPV-positive OSCC has been steadily rising and parallels the rise in rates of oral sex and oral HPV exposure (Figure 1). ${ }^{35}$

There are significant differences between HPV-positive and HPV-negative OSCC. Patients with HPV-positive OSCC tend to be younger by about 10 years, usually are nonsmokers, have higher numbers of vaginal and oral sex partners, and have a much better response to treatment. ${ }^{36,37} \mathrm{~A}$ recent study showed that HPV-positive patients had a $69 \%$ reduction in risk of death compared with HPV-negative patients, with a mean survival of 131 versus 20 months. ${ }^{35}$ The incidence of both HPV-associated and HPV-unassociated HNSCC is more than 2-fold higher among men than women, with a ratio from 2:1 to 5:1. The prevalence of oral HPV infection in a US study was approximately 3 -fold higher in men than women $(10.1 \%$ vs $3.6 \%)$ and HPV-16 prevalence was more than 5 -fold higher, which could explain the higher incidence of HPVpositive OSCC among men. ${ }^{38}$ Possible reasons for this difference include higher risk of HPV acquisition from oral sex on women versus men and higher rates of systemic antibody response to HPV genital infection in women versus men. ${ }^{38}$

By 2020, the number of HPV-positive OSCCs is projected to surpass the number of cervical cancers. ${ }^{35}$ Clinical studies to evaluate the effectiveness of HPV vaccines to prevent OSCC are in developmental stages.

${ }^{39}$ It is highly likely that as these studies are completed and as surveillance rates monitor OSCC incidence in HPV-vaccinated populations, prevention of head and neck cancers may prove to be an additional benefit of HPV vaccination, particularly for men, who are at higher risk. 